\title{
Potential Woody Biomass Supply Chain Scenarios: A Conceptual Study
}

\author{
Evelyn A. Thomchick ${ }^{1}$ and Kusumal Ruamsook ${ }^{2}$ \\ ${ }^{1}$ Department of Supply Chain \& Information Systems, \\ The Pennsylvania State University, USA \\ Ethomcick@psu.edu \\ ${ }^{2}$ Center for Supply Chain Research, The Pennsylvania State University, USA \\ Kusumal@psu.edu
}

\begin{abstract}
The interconnectivity among various business entities and physical functions of woody biomass supply chains requires a system-wide perspective. Extant studies largely focus on individual business units or sets of activities. This paper takes a supply chain perspective to gain an understanding of potential woody biomass supply chains. The study draws insights from an extensive review of literature to conceptualize potential woody biomass supply chain scenarios. Three woody biomass supply chain scenarios and associated logistics activities were defined from the analysis of literature content. They are woody biomass sourcing from forest product manufacturers, forest landowners, and biomass pre-processers. Findings suggest that woody biomass as a marketable commodity creates business opportunities for loggers and forest product manufacturers. In moving forward, infrastructure and technological development is vital, encompassing logging capability and transportation and industrial infrastructure.
\end{abstract}

Keywords: Woody biomass, logistics strategies, supply chain scenarios.

\section{Introduction}

Diminishing fossil fuel resources, increased competition for those fuels, and a growing realization of the economic and environmental impacts of the dependence on fossil fuels have led to a need to develop renewable energy resources. Bio-energy is one potential component of a renewable energy scenario for the future, accounting for approximately half (49\%) of total renewable energy produced and consumed in the United States in 2012. A wide variety of biomass feedstock is currently used to produce bio-energy, ranging from woody biomass, agricultural wastes, to urban wastes. Of these feedstock varieties, woody biomass accounted for nearly half (45\%) of the total biomass-based renewable energy consumed in 2012 (US Energy Information Administration, 2013). These figures demonstrate the considerable contribution of bio-energy, notably woody biomass-based energy, for national renewable energy effort. 
However, managing biomass feedstock supply and its associated logistics activities are persistent issues. Intrinsically low in bulk densities, biomass feedstock creates logistics challenges in terms of its volume that has to be handled, stored, and transported (Benjamin et al., 2009; Damery and Benjamin, 2007; Sokhansanj and Fenton, 2006; Weiner, 2010). Given the low value of biomass materials and logistics challenges involved, the costs of moving biomass feedstock from supply sources to a biorefinery plant can be prohibitive and often exceed market values for the biomass itself (Kram, 2008; Nicholls et al., 2008).

Managerial predicaments also arise due to the many business entities that make up a woody biomass supply chain. These entities perform two important physical functions of a supply chain. The first function involves production, encompassing forest landowners who produce forest materials; loggers who harvest and convert trees into logs or wood chips; forest product manufacturers whose process residues produce woody biomass; pre-processors who turn forest materials into processed woody biomass such as wood chips and pellets; and bio-refineries who convert woody biomass into heat, electricity, chemicals, and transportation fuels to serve different customers (Allen et al., 1998; D’Amours et al., 2008; Frisk et al., 2010; Sokhansanj and Fenton, 2006). The second function involves logistics of moving the various stages of products from one point in the supply chain to the next, encompassing key activities such as transportation, materials handling, warehousing and storage, and inventory control (Coyle et al., 2008; Fisher, 1997).

The interconnectivity among various entities, the associated physical functions, and supply sourcing challenges require a total supply chain perspective. Yet, extant studies on woody biomass largely focus on individual entities or sets of activities. The gap in research, coupled with the still evolving nature of the industry, lead to woody biomass supply chains that are currently not well perceived. The primary objective of this paper is to conceptualize potential supply chain scenarios associated with woody biomass. Insights gained are imperative as a basis for further research to promote economically feasible bio-energy as a component of renewable energy scenario for the future.

\section{Methodology}

To conceptualize and evaluate potential woody biomass supply chain scenarios, the study draws insights from extensive review of literature. Journal articles in the areas of supply chain and logistics, forest products, biomass feedstock, and bio-energy were selected from archival material available electronically at ProQuest and Academic Search Complete. Other principal data sources are the government and organization websites such as the US Energy Information Administration, the US Forest Service, and the International Energy Agency. Along with these data sources, informal interviews with five researchers in the fields of forest resources, agricultural sciences, and biomass energy were conducted to clarify and verify insights drawn from the literature. 
Over 800 pages of documents were examined and coded on three levels according to Glaser and Strauss (1967) and Strauss and Corbin (1998). In the first level, key activities pertinent to the production and logistics functions of supplying woody biomass to a bio-refinery are identified, and the properties that characterize each activity are examined. Then, in the second level, we made connections between categories (in this case, the key activities identified above) by exploring the conditions and interactions that influence the processes of supplying woody biomass. This coding allowed us to integrate data into core categories or potential woody biomass supply chain scenarios. Then, using the core supply chain scenarios as a guide, we selectively coded the existing data obtained from literature survey and additional data gathered from the informal interviews to describe each scenario. At the end of this third-level coding, we have established the descriptions of potential supply chain scenarios.

\section{Conceptualizing Woody Biomass Supply Chain Scenarios}

Three potential woody biomass supply chain scenarios are identified and depicted in Figures 1-3. They are: (1) woody biomass sourcing from forest product manufacturers, (2) woody biomass sourcing from forest landowners, and (3) woody biomass sourcing from biomass pre-processers. We briefly describe each scenario in turn as follows.

\subsection{Woody Biomass Sourcing from Forest Product Manufacturers}

The first scenario, depicted in Figure 1, is currently preferred by most bio-refineries (Morgan, 2009).

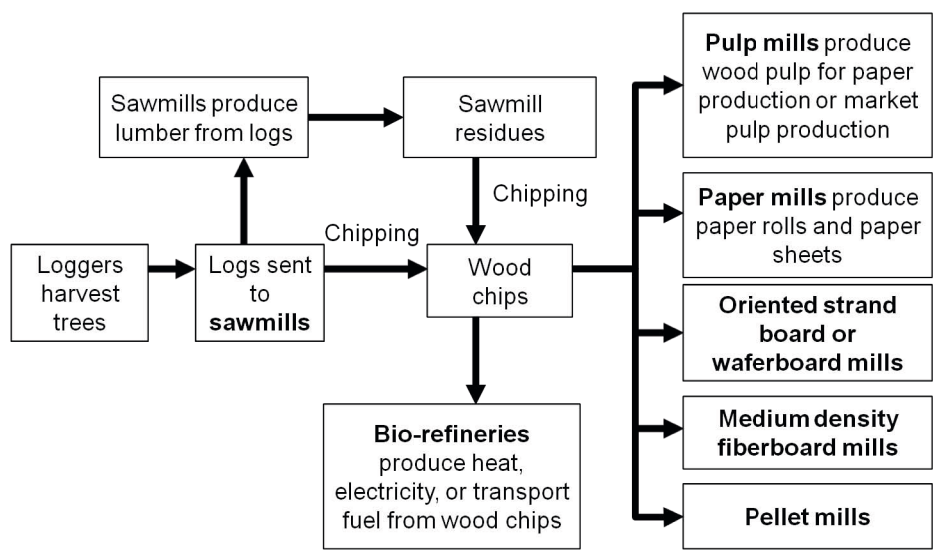

Fig. 1. Woody Biomass Sourcing from Forest Product Manufacturers

In this scenario, residues produced by primary wood processors, such as sawmills and their lumber customers, are the primary feedstock for both the bio-refineries and secondary forest product manufacturers such as pulp mills, paper mills, and pellet 
mills (Ray, 2010). Classified as industrial private landowners, these forest product manufacturers possess large forest assets for uses in their manufacturing requirements (Benjamin et al., 2009; Frisk et al., 2010; IBISWorld, 2009; McDill, 2011). They contract independent loggers for harvesting timber and delivering logs from their forestland to their production facilities (Myers and Richards, 2003). In general, approximately 80 percent of the output loggers generated-typically the lower part of the tree that has a larger diameter, and thus a higher value-is transported directly to a nearby sawmill for processing. The upper, thinner parts of the tree that have lower value are commonly delivered to pulp mills and paper mills (Crooks, 2005; D'Amours et al., 2008; Frisk et al., 2010; IBISWorld, 2009, 2010). These loggers typically use trucks and equipment they owned or leased to make the deliveries to the mills (IBISWorld, 2010), although in some cases transport service providers or contract haulers (e.g. trucking companies and rail carriers) may also be involved (Bolding et al., 2009). In turn, the mills deliver mill chips to the bio-refineries according to the arrangement between the parties, which vary in terms of transportation mode used, and size and frequency of deliveries (Liu, 2010; McDill, 2011; Roth, 2010).

\subsection{Woody Biomass Sourcing from Forest Landowners}

The second scenario, depicted in Figure 2, makes use of forest materials that contribute the potentially most abundant sources of woody biomass in the United States (Nicholls et al., 2008).

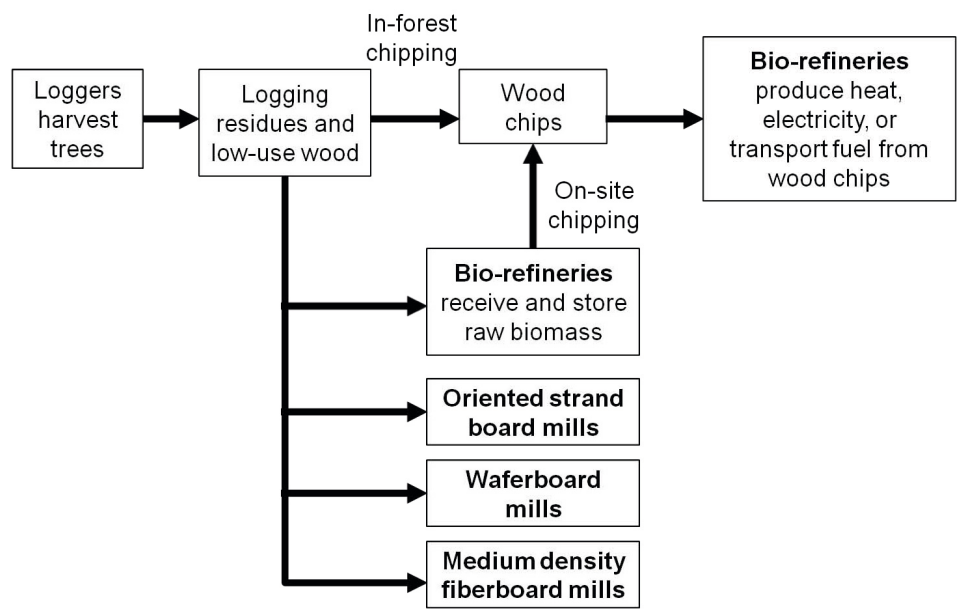

Fig. 2. Woody Biomass Sourcing from Forest Landowners

In this scenario, forest biomass is sourced from landowners that can be public entities (e.g. federal, state, and local and municipal land and forests), private industrial entities (e.g. saw mills, and pulp and paper mills), or non-industrial private entities (e.g. individuals or corporations other than forest product industry) (Biomass Research and Development Board, 2008b; D'Amours et al., 2008). As in the first 
scenario, forest landowners contract loggers for felling standing timber, delivering the outputs, and disposing logging residues. Decisions on the methods of residue disposal (e.g. piling and burning, scattering throughout a site to decompose, and processing as biomass) may be left to the loggers, or set forth by landowners and third-party environmental certification standards for sustainable forest management practices (Benjamin et al., 2009; Elmore, 2009; Yepsen, 2008).

In turn, bio-refineries transact with the loggers for the forest biomass. Biomass can be delivered in either chipped or non-chipped forms. The former involves in-forest chipping, which is well integrated into existing timber harvesting systems (D'Amours et al., 2008; Gunnarsson et al., 2004). In this case, loggers with portable woodchipping equipment produce wood chips from logging residues and from whole trees of non-merchantable quality for direct sale to bio-refineries and other buyers such as pulp and paper mills (D'Amours et al., 2008). Unlike clean chip by-products from forest product manufacturers, these logging chips (also called dirty chips and hog fuel) are characterized by high moisture and varied physical quality in terms of size, shape, and chemical makeup (Benjamin et al., 2009; Kimbell et al., 2009; Kram, 2008; Weiner, 2010; Yepsen, 2008). These characteristics render biomass that has low net energy density by mass, is unsuitable for long-term storage, and is uneconomical for long distance transportation (Crooks, 2005; Goldstein, 2006; Jackson et al., 2010; Liu, 2010; McDill, 2011; Wallace, 2011; Richard, 2011). Coupled with the often geographically dispersed forest lands, transportation cost could easily exceed the costs of biomass itself (Bolding et al., 2009).

Alternatively, non-chipped forest biomass can be transported to bio-refinery facilities where it will be chipped using a larger-scale, more powerful stationary chipper (D'Amours et al., 2008). In comparison to the in-forest chipping, this alternative gives the bio-refineries greater control over the chipping process and offers a cost advantage gained from economies of scale and the powerful equipment used. These advantages, however, are offset by the more expensive cost of transporting non-chipped, as opposed to chipped, forest biomass to the refinery facilities (D'Amours et al., 2008; Jackson et al., 2010).

\subsection{Woody Biomass Sourcing from Biomass Pre-processers}

The third scenario, illustrated in Figure 3, depicts business opportunities that emerged from the need to pre-process and pre-treat biomass to alleviate production and logistics issues pertinent to biomass.

In this scenario, woody biomass suppliers are relatively large facilities with storage capacity and flexible system capable to pre-process and pre-treat a wide range of biomass materials. The biomass supply chain in this scenario resembles that of a huband-spoke system of biomass processing and distribution (Carolan et al., 2007; Roth, 2010; Yepsen, 2008, 2009). A typical biomass pre-processer assumes a role of an intermediary who engages in securing and establishing contracts for various types of biomass from various sources. It also manages the collection, storage, pre-process, and delivery of biomass to the bio-refinery and other biomass users (Carolan et al., 2007; Sokhansanj and Fenton, 2006). 
A pre-processor's large-scale, flexible system permits physical transformation (e.g. pre-processed briquettes, pellets, and torrefied biomass) and chemical transformation (e.g. pre-treated to alter chemical component) of a wide range of biomass feedstock to satisfy the quality and quantity requirements of biomass users before making delivery (Roth, 2010; Yepsen, 2008). Hence, aside from improving the quality of biomass as feedstock, these processing technologies are also logistically advantageous, making it possible to economically transport biomass over greater distances and to store large quantities of biomass for longer periods of time. Production cost advantage is also achieved because of economies of scope gained from the variety of feedstock used and flexible product mix, and economies of production scale and powerful equipment used (Carolan et al., 2007; Jackson et al., 2010; Sokhansanj and Fenton, 2006; Taylor et al., 2010).

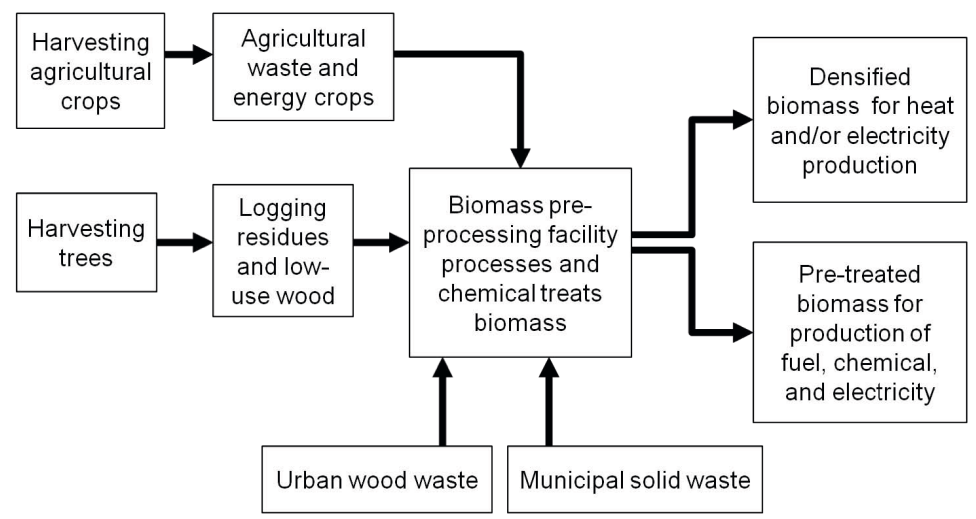

Fig. 3. Woody Biomass Sourcing from Biomass Pre-Processing Facilities

\section{Conclusion}

This conceptual study identifies three potential woody biomass supply chains and reveals the roles and interactions between different members in performing the production and logistics functions of the supply chains. Three important implications in moving woody biomass-based bio-energy forward arise from the findings summarized in Table 1.

First, loggers play an important production role in all three scenarios. To take advantage of the new biomass market opportunities, logging capacities must be developed and new managerial and operational practices must be devised to integrate the existing operations and emerging biomass business (Benjamin et al., 2009; Biomass Research and Development Board, 2008b; Damery and Benjamin, 2007; Elmore, 2009; Kram, 2008; Yepsen, 2008, 2009).

Second, forest product manufacturers possess technological and infrastructural advantages that render them competitive as biomass suppliers. They have access to their abundant industrial forestlands, well-established transportation systems, and the on-site infrastructure for pre-processing, storage, and handling of woody biomass. The new markets of biomass as feedstock for bio-energy present great opportunities 
for business expansion that leverage these existing capital investment and resources (Benjamin et al., 2009; Frisk et al., 2010 Jackson et al., 2010; Sklar, 2008). A more vertically integrated avenue is to expand into the bio-refinery business and become an "integrated forest product bio-refinery" enterprise that produces bio-products (e.g. heat, transport fuel, and bio-chemical) in addition to conventional forest products (Damery and Benjamin, 2007; Feng et al., 2010; Kimbell et al., 2009).

Table 1. Woody Biomass Supply Chain Scenarios: Key Parties, Roles, and Advantages/ Disadvatages

\begin{tabular}{|c|c|c|c|c|c|c|c|}
\hline Scenarios & $\begin{array}{c}\text { Forest } \\
\text { material } \\
\text { production }\end{array}$ & Harvesting & $\begin{array}{c}\text { Physical } \\
\text { pre- } \\
\text { processing }\end{array}$ & $\begin{array}{c}\text { Chemical } \\
\text { pre- } \\
\text { treating }\end{array}$ & $\begin{array}{l}\text { Biomass } \\
\text { delivery }\end{array}$ & $\begin{array}{l}\text { Biomass } \\
\text { storage }\end{array}$ & $\begin{array}{c}\text { Advantage/ } \\
\text { Disadvantage to } \\
\text { Biomass Buyers }\end{array}$ \\
\hline $\begin{array}{l}\text { Sourcing } \\
\text { from } \\
\text { Forest } \\
\text { Product } \\
\text { Mfr: (FPM) }\end{array}$ & FPM & $\begin{array}{l}\text { Logger } \\
\text { contracted } \\
\text { by FPM }\end{array}$ & FPM & $\begin{array}{l}\text { Bio- } \\
\text { refinery }\end{array}$ & $\begin{array}{c}\text { Between } \\
\text { bio-refinery } \\
\text { and FPM }\end{array}$ & $\begin{array}{c}\text { Bio- } \\
\text { refinery }\end{array}$ & $\begin{array}{l}\text { Established } \\
\text { sector; Clean } \\
\text { chips } \\
\text { - Supply } \\
\text { depending on } \\
\text { FPM } \\
\text { production }\end{array}$ \\
\hline $\begin{array}{l}\text { Sourcing } \\
\text { from } \\
\text { Forest } \\
\text { Landowner } \\
\text { (FLO) }\end{array}$ & FLO & $\begin{array}{l}\text { Logger } \\
\text { contracted } \\
\text { by FLO }\end{array}$ & $\begin{array}{l}\text { Logger or } \\
\text { bio-refinery }\end{array}$ & $\begin{array}{l}\text { Bio- } \\
\text { refinery }\end{array}$ & $\begin{array}{l}\text { Bio- } \\
\text { refinery } \\
\text { arranges } \\
\text { own } \\
\text { shipment } \\
\text { with } \\
\text { loggers }\end{array}$ & $\begin{array}{l}\text { Bio- } \\
\text { refinery }\end{array}$ & $\begin{array}{l}\text { - Established } \\
\text { sector, } \\
\text { potentially } \\
\text { most abundant } \\
\text { sources } \\
\text { - Dirty chip; high } \\
\text { transport cost }\end{array}$ \\
\hline $\begin{array}{l}\text { Sourcing } \\
\text { from Pre- } \\
\text { processer } \\
\text { (PP) }\end{array}$ & FLO & $\begin{array}{l}\text { Logger } \\
\text { contracted } \\
\text { by PP }\end{array}$ & PP & PP & $\begin{array}{l}\text { Between } \\
\text { bio-refinery } \\
\text { and PP }\end{array}$ & PP & $\begin{array}{l}\text { - Economy of } \\
\text { scale and } \\
\text { scope; } \\
\text { feedstock to } \\
\text { specification } \\
\text { - Not yet } \\
\text { established } \\
\text { sector }\end{array}$ \\
\hline
\end{tabular}

Finally, infrastructure development is vital to enhance reliability and efficiency of the production and logistics functions of woody biomass supply chains. Transportation infrastructure, in particular, is much needed to tap into the abundant, yet highly dispersed forest biomass resources. Additionally, an extensive industrial infrastructure is required to advance the current experimental operations to commercial stages. Industrial infrastructure encompasses not only the bio-refinery facility itself, but also pre-processing and treatment facilities, and communication technology needed to improve logging and biomass harvest efficiencies (Benjamin et al., 2009; Jackson et al., 2010; Kimbell et al., 2009).

Acknowledgments. This work was funded by a Pennsylvania State Sustainability Seed Grant awarded by the Pennsylvania State Institutes of Energy and the Environment (PSIEE). We thank Dr. Jude Liu, Dr. Marc E. McDill, Dr. Tom Richard, Dr. Gregory W. Roth, and Mr. Bob Wallace for their valuable insights on the woody biomass, forest management, and renewable energy industries. 


\section{References}

1. Allen, J., Browne, M., Hunter, A., Boyd, J., Palmer, H.: Logistics Management and Costs of Biomass Fuel Supply. International Journal of Physical Distribution and Logistics Management 28(6), 463-477 (1998)

2. Benjamin, J., Lilieholm, R.J., Damery, D.: Challenges and Opportunities for the Northeastern Forest Bioindustry. Journal of Forestry 107(3), 125-131 (2009)

3. Bolding, M.C., Kellogg, L.D., Davis, C.T.: Productivity and Costs of an Integrated Mechanical Forest Fuel Reduction Operation in Southwest Oregon. Forest Products Journal 59(3), 35-47 (2009)

4. Carolan, J.E., Joshi, S.V., Dale, B.E.: Technical and Financial Feasibility Analysis of Distributed Bioprocessing Using Regional Biomass Pre-Processing Enterprises. Journal of Agricultural \& Food Industrial Organization, Special Issue: Explorations in Biofuels Economics, Policy, and History 5(2), 1-29 (2007)

5. Coyle, J.J., Langley Jr., C.J., Gibson, B.J., Novack, R.A., Bardi, E.: Supply Chain Management: A Logistics Perspective. South-Western Cengage Learning, Mason (2008)

6. Crooks, A.M.: Protecting Forests and Supporting Renewable Energy. BioCycle 46(4), 68$71(2005)$

7. D'Amours, S., Rönnqvist, M., Weintraub, A.: Using Operational Research for Supply Chain Planning in the Forest Products Industry. INFOR 46(4), 265-281 (2008)

8. Damery, D.T., Benjamin, J.: The Northeast Forest Bio-products Puzzle. Forest Products Journal 57(11), 14-15 (2007)

9. Elmore, C.: No Chip Left Behind. OEM Off-Highway 27(3), 24-26 (2009)

10. Feng, Y., D' Amours, S., LeBel, L., Nourelfath, M.: Integrated Bio-Refinery and Forest Products Supply Chain Network Design Using Mathematical Programming Approach. Report CIRRELT-2010-50 (November 2010)

11. Fisher, M.L.: What is the Right Supply Chain for Your Product? Harvard Business Review, 105-116 (March-April 1997)

12. Frisk, M., Göthe-Lundgren, M., Jörnsten, K., Rönnqvist, M.: Cost Allocation in Collaborative Forest Transportation. European Journal of Operational Research 205(2), 448-458 (2010)

13. Glaser, B.G., Strauss, A.: The Discovery of Grounded Theory: Strategies for Qualitative Research, Aldine, Chicago, IL (1967)

14. Goldstein, N.: Woody Biomass as Renewable Energy Source. BioCycle 47(11), 29-31 (2006)

15. Gunnarsson, H., Mikael, R., Lundgren, J.T.: Supply Chain Modeling of Forest Fuel. European Journal of Operational Research 158(1), 103-123 (2004)

16. IBISWorld: Timber Services in the US Industry Report [11311] (December 2009)

17. IBISWorld: Logging in the US Industry Report [11331] (June 2010)

18. Jackson, S.W., Rials, T.G., Taylor, A.M., Bozell, J.G., Norris, K.M.: Wood2Energy: A State of the Science and Technology Report. The University of Tennessee (May 2010)

19. Kimbell, A.R., Thomas, M., Hutch, B., Bowyer, J.L., Argow, K.A.: More Energy from Wood: What Are the Prospects? Journal of Forestry 107(5), 267-272 (2009)

20. Kram, J.W.: Is Biomass Harvesting Sustainable? Biomass Magazine (September 2008)

21. Liu, J.: Assistant Professor of Agricultural and Biological Engineers, Department of Agricultural and Biological Engineering, Agricultural Sciences, Pennsylvania State University. Personal conversation with authors (October 21, 2010) 
22. McDill, M.E.: Associate Professor of Forest Management and Program Chair for Forest Science, School of Forest Resources, Agricultural Sciences, Pennsylvania State University. Personal conversation with authors (January 25 and September 16, 2011)

23. Morgan, T.A.: Woody Biomass: Can Forests Fuel Our Future? Montana Business Quarterly 47(4), 2-6 (2009)

24. Myers, J., Richards, E.W.: Supporting Wood Supply Chain Decisions with Simulation for a Mill in Northwestern BC. INFOR 41(3), 213 (2003)

25. Nicholls, D.L., Monserud, R.A., Dykstra, D.P.: Biomass Utilization for Bioenergy in the Western United States. Forest Products Journal 58(1/2), 6-16 (2008)

26. Ray, C.D.: Project-Based Overview of Woody Biomass Initiatives in the Generation of Thermal Energy, Electricity, and Transportation Fuels in the Eastern Hardwood Region of the United States. Report submitted to USDA Forest Service (March 2010)

27. Richard, T.: Director of Penn State Institutes of Energy and the Environment, Professor of Biological Engineering, Penn State University. Personal conversation with authors (August 31, 2011)

28. Roth, G.W.: Professor of Agronomy, Department of Crop and Soil Sciences, Agricultural Sciences, Pennsylvania State University. Personal conversation with authors (October 20, 2010)

29. Sklar, T.: Ethanol from Wood Waste an Opportunity for Refiners. Oil \& Gas Journal 106(21), 54-59 (2008)

30. Sokhansanj, S., Fenton, J.: Cost Benefit of Biomass Supply and Pre-Processing. Synthesis Paper, A BIOCAP Research Integration Program (March 2006)

31. Strauss, A., Corbin, J.: Basics of Qualitative Research: Grounded Theory Procedures and Techniques. Sage, Newbury Park (1998)

32. Taylor, E.L., Holley, A.G., Blazier, M.: Comparisons of In-Woods Densification Options in the Western Gulf. Rutgers eXtension (last modified March 12, 2010)

33. US Energy Information Administration: Monthly Energy Review. Table 10.1 Renewable Energy Production and Consumption by Source (April 2013)

34. Wallace, R.: Associate, BoozïAllenïHamilton. Email sent to authors, August 12, and conference call with authors August 17 (2011)

35. Weiner, L.: The Ripple Effect. Minority Business Entrepreneur 27(2), 30-32 (2010)

36. Yepsen, R.: Forest Thinning Strategies for Biomass Utilization. BioCycle 49(12), 32-36 (2008)

37. Yepsen, R.: Wood Processing Innovations. BioCycle 50(2), 25-26 (2009) 